Article

\title{
Teaching Scenario-Based Planning for Sustainable Landscape Development: An Evaluation of Learning Effects in the Cagliari Studio Workshop
}

\section{Christian Albert ${ }^{1,2, *}$, Christina von Haaren ${ }^{1}$, Juan Carlos Vargas-Moreno ${ }^{3}$ and Carl Steinitz ${ }^{4,5}$}

1 Institute of Environmental Planning, Leibniz Universität Hannover, Herrenhäuser Str. 2, 30419 Hanover, Germany; E-Mail: haaren@umwelt.uni-hannover.de

2 Department Environmental Politics, Helmholtz Centre for Environmental Research-UFZ, Permoserstraße 15, 04318 Leipzig, Germany; E-Mail: christian.albert@ufz.de

3 GeoAdaptive LLC, 250 Summer Str., Boston, MA 02210, USA; E-Mail: jcvargas@geoadaptive.com

4 Centre for Advanced Spatial Analysis, University College London, 90 Tottenham Court Road, W1T 4TJ London, UK

5 Graduate School of Design, Harvard University, 48 Quincy Street, Gund Hall, Cambridge, MA 02138,USA; E-Mail: steinitz@gsd.harvard.edu

* Author to whom correspondence should be addressed; E-Mail: albert@umwelt.uni-hannover.de; Tel.: +49-511-762-2652; Fax: +49-511-762-3791.

Academic Editor: Marc A. Rosen

Received: 19 January 2015 / Accepted: 19 May 2015 / Published: 28 May 2015

\begin{abstract}
This paper investigates the contributions of an intensive educational workshop to advance students' understanding and skills for collaborative, scenario-based landscape planning. The research design involves a case study workshop with thirty international students and several regional experts as well as a multi-stage, in-process evaluation. The workshop resulted in six different alternative futures for the region of Cagliari, Italy, and a seventh combined version that was considered best by regional reviewers. The students' learning evaluation showed substantial advances in their relevant understanding and skills. Key aspects of the workshop pedagogy and the evaluation are discussed, and recommendations for future applications presented.
\end{abstract}

Keywords: sustainable landscape development; landscape planning; scenarios; education; evaluation 


\section{Introduction}

Students of landscape planning should be equipped with competencies for collaborative, scenario-based planning approaches in support of efforts for sustainable development. Scenario-based approaches assume alternative development trends and explore their respective consequences (e.g., [1-4]). They are increasingly applied to address the high degree of complexity and uncertainty inherent in planning for future landscape change [5-8].

Gaining experience in interdisciplinary collaboration is essential for students today because planning processes increasingly involve scientists, policy makers, and stakeholders, who must address current issues by jointly generating knowledge (e.g., [9-13]). Planning is no longer seen as a solely expert-based endeavor, but rather a public process that involves active participation of relevant actors [14-16].

Thus, planning education needs to find effective means for supporting students to develop knowledge and know-how for such collaborative, scenario-based approaches. One approach that is well suited for teaching both planning understanding and skills is the educational studio or workshop pedagogy $(c f .[13,17,18])$. Planning workshops are organized around a realistic problem in a specific region and involve analysis, design, policy, and strategy development [19]. They may last from a few hours to one or two semesters and serve as an experimental laboratory for "learning by doing" [20] in order to test and practice planning skills and methods.

To effectively exploit the potentials of workshop pedagogy, and to achieve and sustain high educational quality, evaluations - and iterative learning from their findings - are an essential instrument [21]. However, formal evaluations, institutionalized in many educational programs, often do not shed light on the rather implicit issues of conceptual understanding and planning skills. Scholarly assessments of educational planning workshops provide more detail, but so far focus on other questions.

Several studies addressed students' learning styles and their possible influence on planning performance (e.g., [22-24]). Lusk and Kantrowitz [18] report on the assessment of the effectiveness of an introductory communication methods and professional practice studio to teach written, oral, graphic and integrated communication skills in brief reality based-team projects. Vakil et al. [17] describe a systematic evaluation of a planning workshop course that offered technical assistance to a local community, focusing on pedagogy, student learning, and benefits of communities. They conclude that learning broadens students understanding of different perspectives and objectives for development. Lehmann et al. [25] explore problem-oriented and project-based learning (POPBL) as an innovative learning strategy for sustainable development in engineering education. Grant and Manuel [26] report on efforts for enhancing peer learning (students facilitating each other's learning) in workshops and find that such learning fosters students' confidence in their abilities and expertise. Stoltz and Brown [27] are interested in enhancing the independence of learning in studio teaching and use assessments of content and maturity of thought in student submissions as indicators. In education for sustainability science, relevant competencies have been attributed to three clusters: strategic knowledge including content and methodological knowledge, practical knowledge about bringing knowledge to action, and collaborative knowledge of working in teams and different knowledge communities [13] In a similar vein, Wiek et al. [28,29] propose the following set of core competencies: systems-thinking competence; anticipatory competence; normative competence; strategic competence; and interpersonal competence. In particular, anticipatory competence — the knowledge that can be gained through scenario exercises — has 
been identified as a critical component of sustainability education by many authors [28-30] and Foley et al. [31] explored the usage of studios to build anticipatory competence among students. Finally, Steinitz [32] presents a special issue on landscape planning education, focusing mainly on different cultural traditions and national structures instead of learning effects (e.g., papers by [33,34]).

This paper investigates the extent to which planning workshops can contribute to the development of relevant understanding and skills for scenario-based landscape planning among participating students. It asks two research questions:

- Do short and intensive educational planning workshops advance participating students' planning understanding, defined here as knowledge of the design and procedures of scenario-based planning processes?

- Do educational planning workshops contribute to the development of relevant planning skills among participating students?

The central innovation of the paper lies in the conduct of multi-stage and in-process evaluation research, which so far - to the knowledge of the authors - is non-existent in the literature. The evaluation methods were not selected from a known set, but invented to fit the circumstances.

An educational alternative futures planning workshop in the region of Cagliari, Italy, serves as a case study. The workshop's educational goal was to equip participating students with understanding of and skills for scenario-based planning through the practical involvement in the creation and assessment of alternative futures for the case study area. It was expected that the learning would be reflected in responses to survey questions, statements in interviews, and observed changes of behavior.

The remainder of this paper introduces the evaluation method used, reports on the case study workshop process and its outputs, and describes the results of the workshop evaluation. The results will help to assess the educational effects of planning workshops, and may assist in designing and conducting workshops most likely to achieve learning success.

\section{Methods}

The research design involves the organization and conduct of a workshop case study, and a multi-method approach for the acquisition of evaluation data and its analysis.

\subsection{Case Study Workshop Approach and Methods}

The case study was a one-week educational planning workshop in Sardinia, Italy. The objective of the workshop was to develop and assess alternative futures for the region of Cagliari, the capital of Sardinia. The study area (Figure 1) covered about 14,300 hectares and involved the City of Cagliari, the Molentargius - a breeding ground for flamingos and protected area of international importance-as well as the surrounding urban and rural landscape. Participants were 12 students from Leibniz Universität Hannover (LUH), Germany, and 18 students from Università degli studi di Cagliari (UC), Italy. LUH students were enrolled in Bachelors', Masters' or PhD programs in Landscape Architecture and Environmental Planning. UC students majored in Territorial Engineering and Architecture. The number of female and male participants was almost even (14 to 16) and the average age was 26 years. 


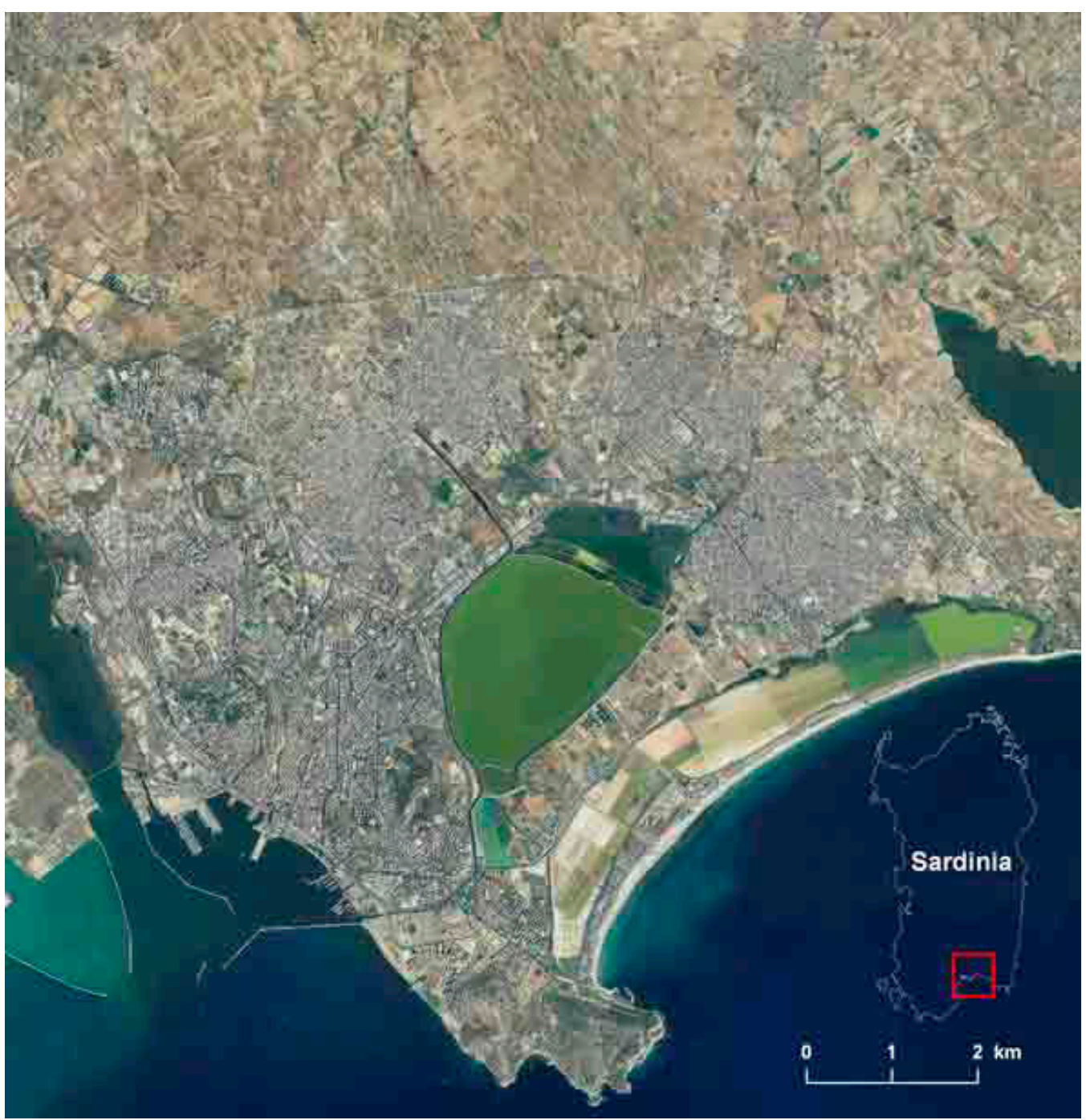

Figure 1. Study area.

The Cagliari workshop was run by Carl Steinitz and based on the Alternative Futures Framework Method [2,4]. For more detailed information on the Cagliari Workshop process and results, please see Steinitz et al. [35] and Steinitz [36]. The framework consists of six questions that need to be addressed in any alternative futures study ( $c f$. [2]; Figures 2 and 4):

- How should the landscape be described?

- How does the landscape operate?

- Is the current landscape working well?

- How might the landscape be altered?

- What difference might the changes cause?

- How should the landscape be changed? 
A FRAMEWORK FOR GEODESIGN

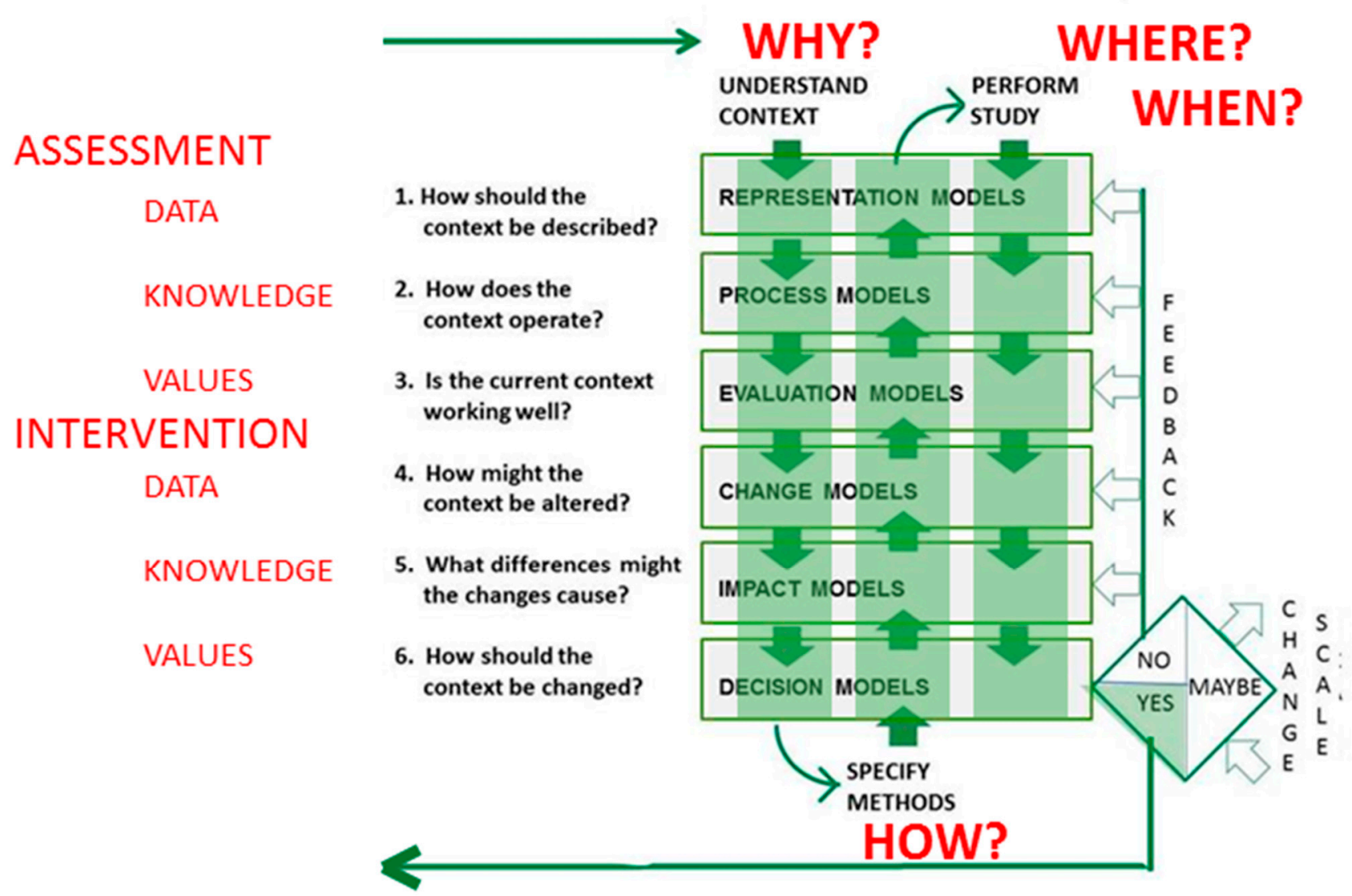

Figure 2. The Steinitz Framework for Alternative Future Studies. Taken from Steinitz [36] with kind permission by the author.

Over the course of a study, each of the six questions is asked three times: first to define the context and scope of the work (WHY questions); second to identify the methods of study (HOW questions), and third, to implement the study method (WHAT, WHERE and WHEN questions).

The practical application of the framework in the Cagliari case study required an adaptation to the workshop schedule and technology. The adapted framework (Figure 3) needed to accommodate the approximately $24 \mathrm{~h}$ of workshop time, a reliance on hand drawn graphics, as well as limited digital data availability and computer access. Due to these constraints, the workshop followed a design-oriented strategy, acknowledging that in practice, study areas of this scale would require comprehensive (GIS-based) assessments. A detailed description of the workshop process is provided in Steinitz et al. [35], from which the following summary is partly quoted: 


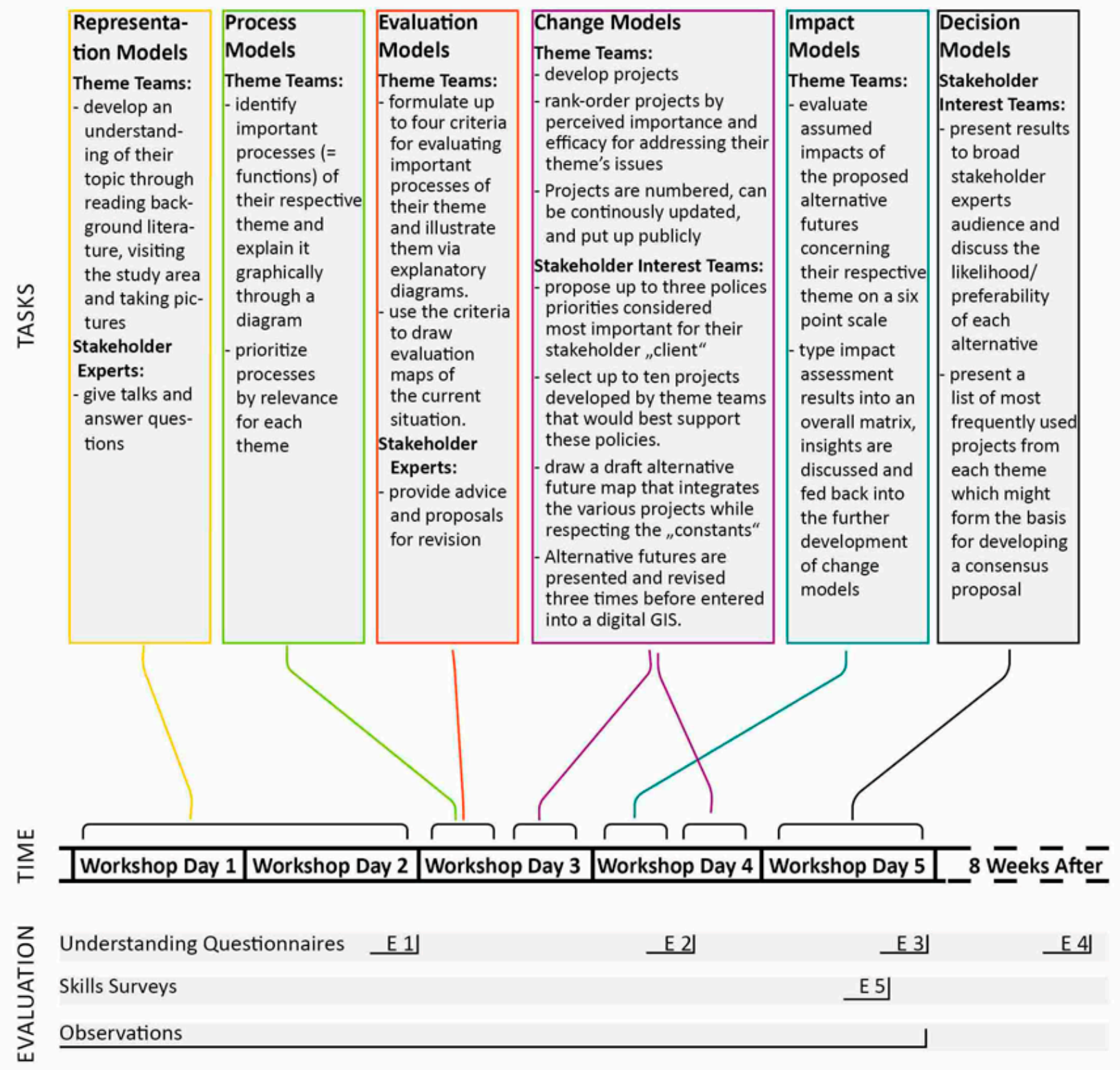

Theme teams Student teams, asked to assess the study area's visual landscape, habitat functions, cultural and recreational use, residentitial development, transport, hydrology, geothermal energy, solar and wind energy, and biomass energy

Stakeholder interest Student teams, asked to represent a certain stakeholder interest: (1) conservationists,

teams

(2) residential, commercial, and industrial developmers, (3) regional planners aiming to implement the Sardinian Landscape Plan, (4) a foundation supporting the use of renewables, (5) the tourism development boards, or (6) several local governments seeking reelection.

Stakeholder experts Local government officials, academics, and representatives from nongovernmental organizations

Projects Spatially explicit proposals for addressing one or more of the issues identified in the evaluation.

Alternative Future Map of proposed land uses for fulfilling the policy priorities of one stakeholder group at a certain time in the future

Constants

Aspects that need to be respected in all alternative futures, including (1) the time horizon of 20 years,

(2) to conserve all protected areas, (3) to accommodate an assumed population growth of four percent, and

(4) to be as self-sufficient with renewable energy as possible.

Evaluation Scale A semi-quantitative scale to assess the consequences of an alternative future concerning the different processes, by using a semi-quantiative scale ( +3 : much better, +1 better, 0 : no change, -1 worse, -3 much worse, -5 function lost)

Figure 3. Overview of workshop processes, evaluation events, and definitions. 
Question 1: How should the landscape be described?

The workshop began with two intensive days for a general introduction to the study area, its history, its current characteristics and future projections. It included a series of lectures by local experts, and a half-day guided fieldtrip throughout the study area. Provided data included current land use, a terrain model, several sector plans and the relevant section of the recently published Sardinian Regional Landscape Plan, many photographs taken by students on the field trip, and Google Earth.

The students were divided into 10 teams that each addressed a different theme of interest (and potential impact) for the future of the region: habitats, the visual landscape, the cultural and recreational landscape, residential development, tourism, transport, hydrology, and due to a particular interest among some German students, geothermal energy, solar and wind energy, and biomass energy. On the field trip, each theme team was asked to be particularly attentive to issues relating to their respective topic, and to take photos illustrating issues of relevance.

Question 2: How does the landscape operate?

To address the second question, each theme team was asked to identify important processes (=function) of their respective theme and to explain it graphically through a diagram. Each team then prioritized its processes by relevance for their respective theme.

Question 3: Is the current landscape working well?

The evaluation of the current landscape and its processes was done by theme groups in formulating up to four criteria for evaluating important processes of their theme, and illustrating them via diagrams. Each team produced a map in two colors where green represented highly valuable elements which sustained the theme-process and which should be protected. Red illustrated areas of problem or threat to the process that should be improved. Stakeholder experts were invited to provide advice.

Question 4: How might the landscape be altered?

Change models were developed in several planning cycles that were intersected by their iterative impact assessments (see Question 5). Theme teams developed diagrams that illustrated proposals for projects to change the processes of their theme. Projects could either aim at protecting valuable areas or improving problem areas. Projects were drawn on thin plastic sheets, color-coded with a different color applicable to each of the 10 theme teams. Projects were then rank-ordered concerning their importance and perceived effectiveness as judged by the team (Figure 5). Each theme team was then given two minutes to concisely present its work. Local experts met with student teams to propose revisions. Finally, all projects were uniquely numbered by their ranks and systematically ordered on a long table. 

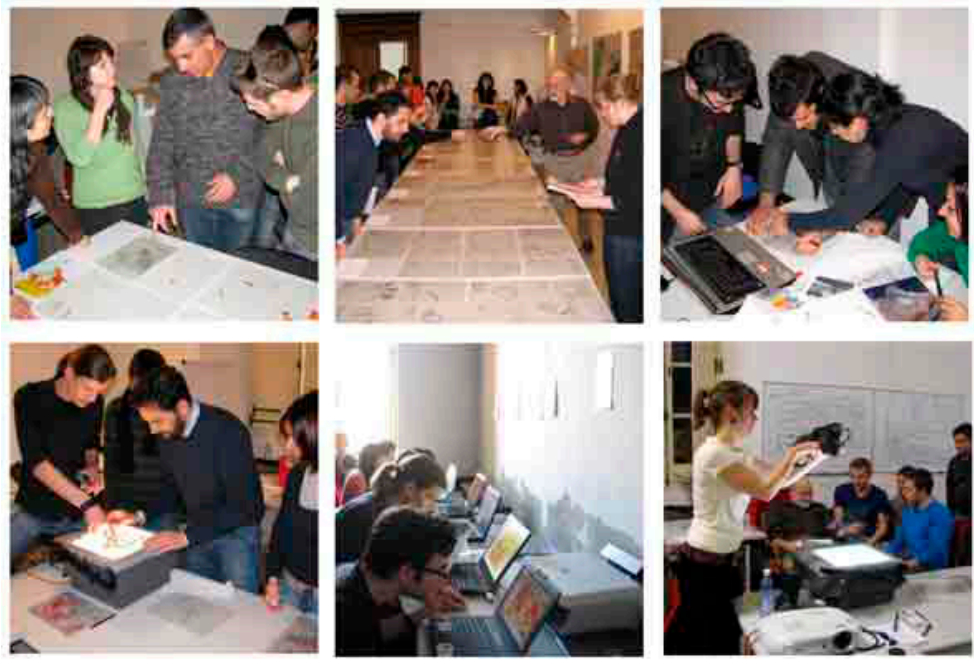

Figure 4. Impressions from the workshop process.

Student participants were organized into six larger teams, each representing a different "stakeholder". These teams were (1) conservationists; (2) residential commercial and industrial developers; (3) regional planners emphasizing the Sardinian Regional Landscape Plan; (4) a foundation for the support of renewable energy; (5) the tourism development board; and (6) the several local governments in the area each seeking reelection.

Each stakeholder team proposed up to three policy objectives considered most important for its stakeholder client and it selected up to ten projects that would best support these policies from the overall set of approximately 150 projects. The teams proposed the policies and selected the projects based on their experience, knowledge gained from discussions with experts, lectures, readings, and the field trip. Each team had to make a proposal for land use changes that would support those objectives over the next 20 years. In addition, each proposal had to accommodate a $4 \%$ growth in population and its concomitant land-use changes and it had to be as self-sufficient in energy as possible. The process of overlaying and combining the drawings was rapid, using an overhead projector as a light table and a digital camera for recording.

The resulting Alternative Future plans were based on a selection of the projects. Any new or varied projects were announced and then numbered and placed on the long table so that they were available for use by anyone else.
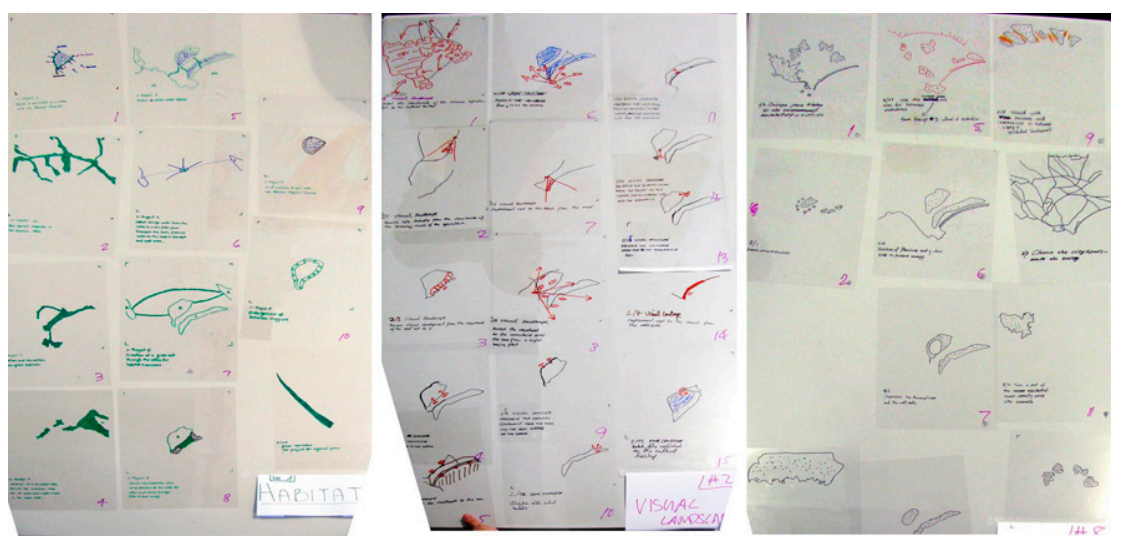

Figure 5. Project proposals, rank-ordered by importance for each theme. 
The students were regrouped into their theme teams and assessed each alternative future concerning its potential impacts to the ten process and evaluation themes. Afterwards, a second planning cycle was started in which the stakeholder teams could revise their proposals. Each altered or new project was again made available for common use.

The second set of plans was presented to the entire group, followed by another round of impact assessments. Each stakeholder team then delegated one person to make a digital representation of each project that could be combined into an alternative future for the final presentation.

Question 5: What predictable differences might the changes cause?

Impact assessments were conducted in that each process theme team evaluated each of the six stakeholder change proposals on a simple scale with six levels. All evaluations were noted on a chart and green or red circles were used to indicate the team that was doing relatively best or worst among the alternatives. The main intent was to engage in a consultation between process theme teams and stakeholder teams to improve the plans in consecutive cycles.

The alternative futures are based on students' assumptions of stakeholder interests, with rows representing interim and final versions of the maps (see Figure 6).

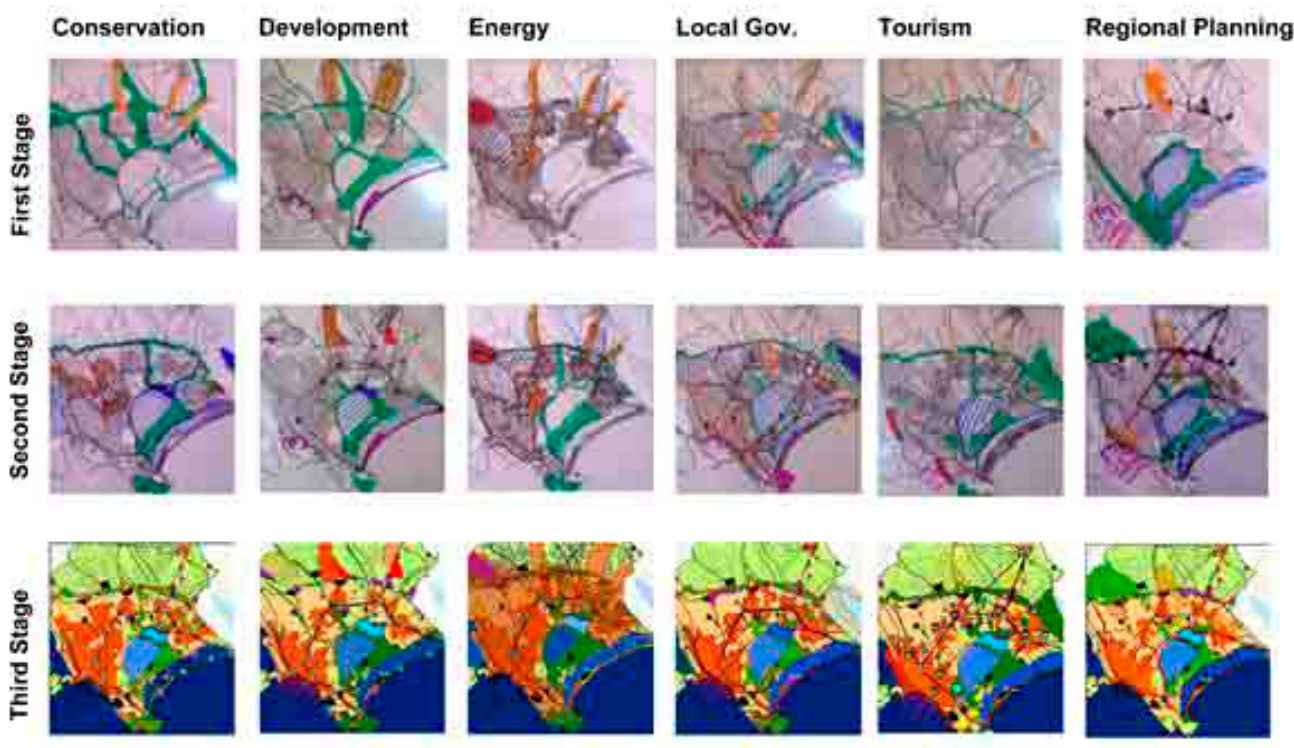

Figure 6. Comparison of the six different alternative futures for the region of Cagliari.

Question 6: How should the landscape be changed?

The Cagliari workshop was not expected to result in a direct decision on the future of the region, and did not do so in practice. However, a presentation and discussion of the results and their potential meanings for future landscape development was organized among the entire workshop group, all of the local experts who had participated, and many additional faculty and students from the University of Cagliari.

Each stakeholder team prepared a graphic product as specified by the faculty. It consisted of (I) three to five images illustrating the stakeholder team's principal policy objectives in order of importance; (II) a slide with all projects chosen of greatest relevance for this stakeholder; (III) a map of existing conditions; (IV) a map of the proposed changes; (V) a comparison of the alternative futures for 
Cagliari (existing and proposed conditions); and (VI) a summary slide showing the selected projects and the resulting alternative future.

In the final presentation that was held entirely in Italian, each team was given ten minutes to present its results before the entire group. Each presentation was followed by questions and answers. Each of the local experts commented on which of the alternative best met his or her expectations for the future development of Cagliari.

Finally, a discussion was organized around the question of whether one should choose among the six alternatives, or whether it was possible to select projects from the alternative and to develop a new plan that could compromise the interests of various stakeholder groups. A frequency assessment of the number of times each of the projects had been selected for integration into the change proposals was used to choose the most-frequently used projects in the alternative futures most liked by the participants. In a rapid experiment in real time, the plastic sheets with the selected projects were overlaid on the overhead projector. Finally, a digital composite image was created (see Figure 7), which was interpreted by the participating local experts as a useful inspiration as a basis for further planning.

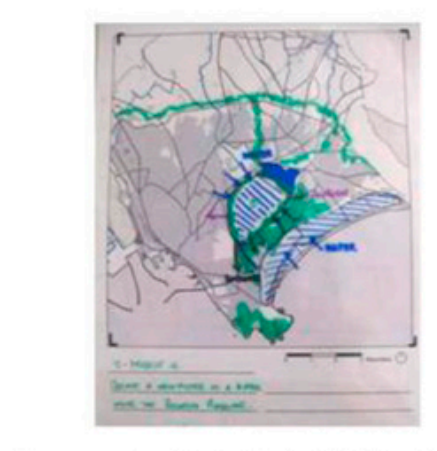

Conserve the Molentargius Wetlands (6x)

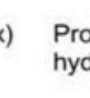

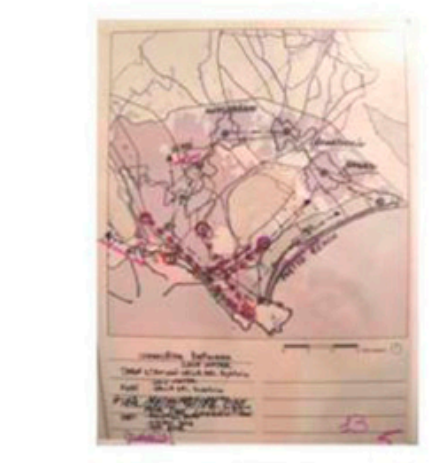

New transport network of metro/ train $(5 x)$
Protect the open water areas and the hydrological system $(6 \mathrm{x})$
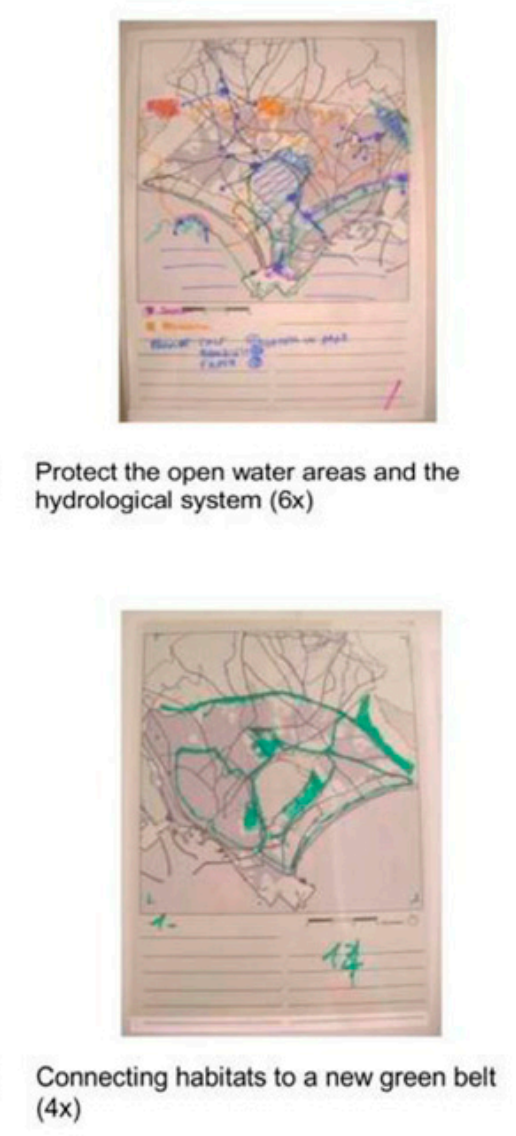
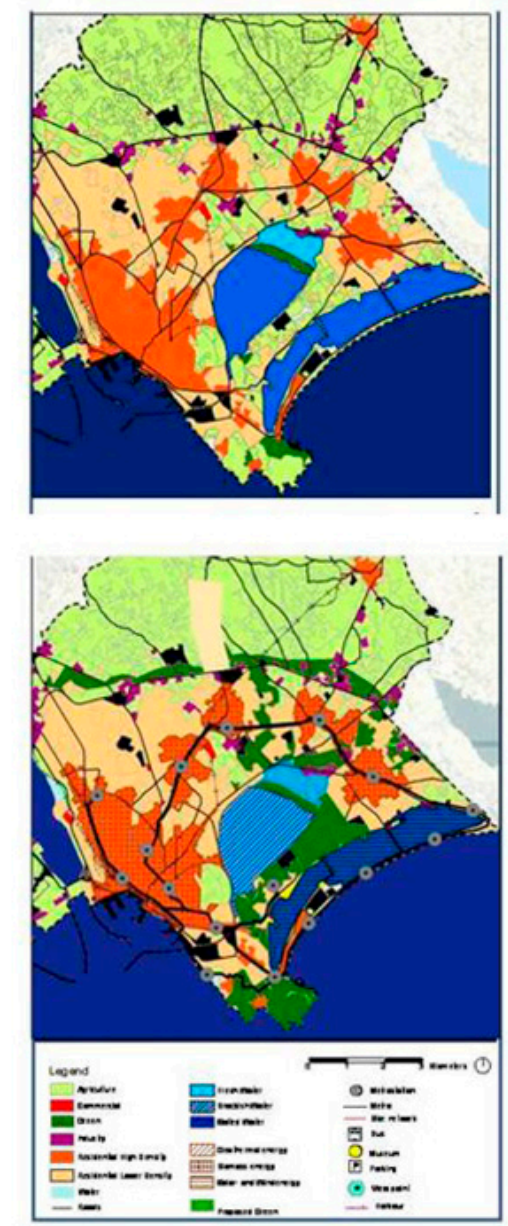

Figure 7. Towards a seventh alternative future. The four diagrams on the left illustrate the most frequently used project proposals by the six stakeholder interest teams (in brackets is the number of teams that integrated the respective proposal). The two maps on the right show the current land use (above) and a new proposal - the seventh alternative future - that integrates the selected projects. 


\subsection{Evaluation Data Gathering Procedures}

Changes in participants' planning understanding were assessed though observations, interviews, a quantitative survey, and an open questionnaire that was handed out three times over the workshop and once two months afterwards (ex-post). The evaluation approach followed the case study approach [37-39] using qualitative methods and triangulation [40-43].

The questionnaire asked students to imagine that they were invited as consultants and charged with the task of designing and conducting a planning study for the case study region. Within this framework, they should answer the following questions on essential issues of planning design and conduct. What is your understanding of the planning problem? What is the planning objective? What would you propose as working steps, methods and tools? What planning products do you suggest and what three criteria should be used to measure success?

The quantitative assessment of the workshop's perceived contribution on the development of alternative futures planning skills was realized through a scaled survey handed out at the end of the workshop as well as nine additional interviews and observations. Unfortunately, the tight workshop schedule made it impossible to hand out two surveys before and after the planning process that would have allowed for assessing changes in stated levels of understanding and skills. The sample was the student participants of the planning workshop $(N=30)$ who all submitted data points. The distribution among sub-groups was as follows: $\mathrm{LUH}=12, \mathrm{UC}=28$, female students $=19$, and male students $=11$. The instrument for the analysis was a set of 23 skills considered of importance for participatory alternative futures planning. This list was derived from the key challenges of contemporary planning (see introduction), as well as the current draft of generic competencies for landscape architecture and planning, developed by the European Council for Landscape Architecture Schools (ECLAS, unpublished). Students were asked to evaluate the perceived degree to which the workshop had contributed to the development of each skill. The survey used five point scales, with five standing for "very much", and one representing "very little".

Observations were conducted independently by one author who was not directly involved in the workshop. The other authors reported participatory observations as part of the teaching team. The observations specifically aimed at identifying changes in student's behavior and verbal expressions that could indicate gained understanding or skills. Observation data was collected through immediate note-taking.

Additional interviews were semi-structured, following an interview guide which supported an ordered but still flexible questioning approach [41]. Interview data was also collected through note-taking. All collected information was transcribed and converted into a typed format as soon as possible to improve the breadth and depth of coverage.

\subsection{Evaluation Data Analysis}

Analyzing the responses to the repeatedly handed out questionnaire on planning understanding followed two pathways. The first approach aimed at gaining insights into changes in planning understanding among all participants. It developed codes for assessing the responses to the open questions, matched the responses to these categories, and determined the proportion of responses 
addressing each category. The second approach addressed individual learning, and looked for changes in series of responses of individual participants.

The data gathered in the quantitative assessment of the workshop's contribution to the development of planning was analyzed using descriptive statistics (Min, Max, Mean and Standard Deviation) (for similar examples, see [44]). Comparisons were drawn between analysis results for the whole student group, as well as for different student cohorts differentiated by home university and sex.

Observations followed an observation protocol that asked observers to focus on particular incidences of student learning such as ease or unease, attention, communications with team members and gestures $[45,46]$. Observations were documented as notes taken while and immediately after the workshop. Notes were sorted into aspects qualifying findings on learning effects and altered planning understanding, identified workshop issues that could be improved, and recommendations for future applications.

\section{Evaluation Results}

\subsection{Workshop Effects on Participants' Planning Understanding}

The questionnaire on planning understanding, which was handed out four times, had an overall response rate of $53 \%$ or 63 copies. Its results, in combination with the data gathered from student reports and observations, suggest that the planning understanding of those who responded changed over the workshop and afterwards.

The evolution of the considered planning challenges between the first and last assessment shows a dramatic increase in mentioning of governance issues from none to about $34 \%$ and a moderate increase in the awareness of multiple problem dimensions from about $65 \%$ to $78 \%$ (Figure $8 \mathrm{~A}$ ). As expected, the rate of responses focusing on only one dimension decreases. An example for the increase in problem dimensions is presented by one student who in the beginning only mentioned the need to integrate considerations of producing renewable energy as a focus of the study. At the third and fourth questionnaire, she also addressed endangered protected areas, unsustainable urban development trends, and development challenges within the city. Another student illustrates the increased consideration of governance in first proposing to develop a plan that "fosters the development of the region without disturbing the sensitive nature", and later emphasizing the need for integrating and balancing the different interests of various stakeholder groups.

The planning objectives proposed by respondents (Figure $8 \mathrm{~B}$ ) decreasingly considered primarily content-related objectives, and increasingly addressed primarily governance related aims. The mid-workshop evaluation saw a particular height in the proportion of responses focusing on governance objectives, and a respective low for content-related ones. This effect might be explained by the pressure of teamwork experienced for the first time for most participants.

A well-suited example for the alteration of the proposed objective is provided by one student who in the first questionnaire suggests the development of new housing areas with the goal of achieving a maximum output of renewable energy generation. In the second assessment, the student proposes to develop "a plan which is acceptable for all participating parties". In the following assessment, he 
argues to find a consensus that "considers all interests at best", and finally "to create a selection of plans which balance as many different interests as possible".
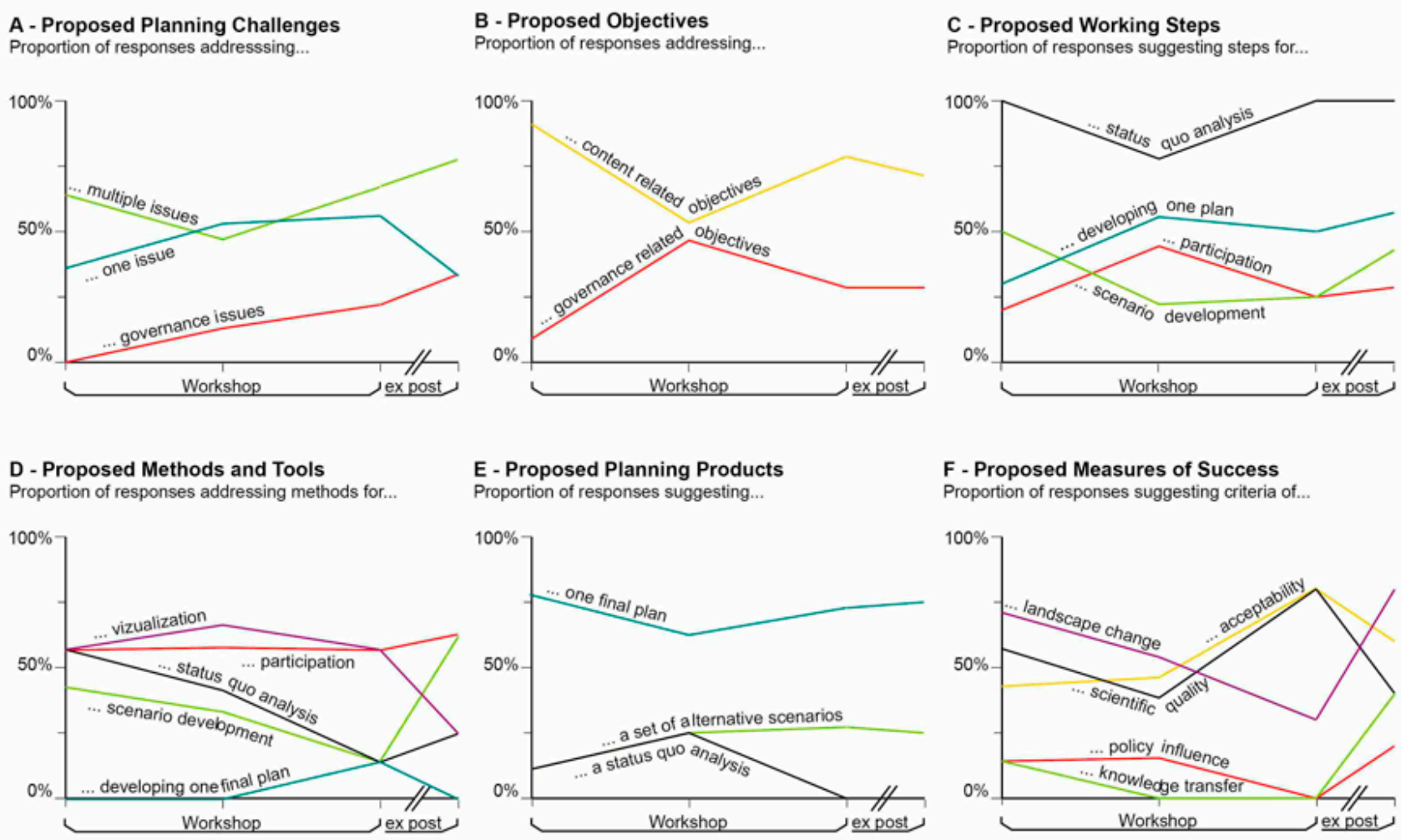

Figure 8. Changes in planning understanding over the workshop and ex-post. Indicated are the proportions of responses matched to each given category. The remainder to 100 percent reflects the proportion of no or not applicable answers. The total numbers of returned questionnaires differed between workshop start, mid-workshop $(N=17$ each $)$, workshop end, and ex-post $(N=15$ each).

The analysis of the proposed working steps (Figure 8C) shows little changes between the first and last assessment in the proportion of responses addressing steps for status quo analysis, participation, and scenario development. The mid-workshop survey again showed reverse trends for these issues. Surprisingly, the percentage of responding students suggesting steps for developing one final plan increased from $30 \%$ to $51 \%$. Some individual responses suggest educational benefits, even although the responses in general show only little changes of understanding. An example is a student who first proposed simple assessments and later on suggested an iterative procedure of expert-based planning and stakeholder consultation.

The answers relating to prosing planning methods (Figure 8D) show a large increase of preferences for scenario methods (from $43 \%$ to $63 \%$ between the first and fourth assessment). One student, for example, proposed brainstorming, project proposals, and presentations in the beginning. Later on, he emphasized individual group work, discussions, and continuous revisions. Finally, he proposed questioning stakeholders as key, highlighting that taking into account the interests of local actors is crucial for planning. Another student already at the beginning of the workshop named public discussions, expert interviews and visualizations as relevant methods and approaches. This 
participant's proposed tools and methods, however, become increasingly sophisticated, including scenario techniques, public discussions, creativity methods, and specific communication procedures like "world café".

Student's responses concerning proposed planning products (Figure 8E) show an increased recognition of the benefits of alternative scenarios (11\% to $25 \%)$ and a decreased mentioning of solely status quo analysis. The proportion of responses suggesting status quo analyses as planning products only slightly decreased. A well-suited example of how students learn to see the relevance of developing alternatives is given by an individual that first proposed a map of "optimal" land use configurations as the final product. Towards the end of the workshop, the student proposed the illustration and description of various scenarios, their evaluative assessment, and comparison between them.

Students' suggestions for measures of success of the hypothetical planning workshop (Figure 8F) confirmed the expectations: Responses mentioning solely product quality criteria (suitability to local conditions, understandability, usefulness, etc.) decreased from $57 \%$ to $40 \%$. At the same time, the proportion of responses considering criteria of landscape change, acceptance, discussions and governance, and knowledge transfer all rose by between 6 to 26 percentage points. Interestingly, comparatively higher proportions of respondents mentioned acceptance criteria and quality criteria in surveys two and three than in the post-workshop survey, suggesting that these learning effects were only of short-term character. A surprisingly large proportion of responses named "knowledge transfer" as a measure of success in the last assessment.

\subsection{Workshop Contributions to Participants'Acquisition of Planning Skills}

The quantitative survey on planning skills had a very high response rate of $96 \%$. It showed that participants perceived the workshop's contribution to the development of planning skills as generally quite positive. Students rated the workshop's effect on all planning skills named in the survey with 4.0 units on the five-point scale (meaning "high" contribution to the skills improvement). For individual skills, the average values given ranged from 3.3 units (medium contribution) to 4.6 units (very high contribution).

The list of 23 individual planning skills and the average ratings provided in decreasing order of perceived workshop contribution are illustrated in Figure 9. Skills given highest ratings include time management, conducting teamwork, and leading and structuring teamwork. Least evaluated were skills for using information technology, presenting in public, as well as up- and downscaling information and knowledge. 
Did the workshop contribute to improving your skills

(1) ... for time management?

(2) ... for conducting teamwork?

(3) ... for leading and structuring teamwork?

(4) ... for considering critique in developing planning proposals?

(5) ... for organizing complex problems?

(6) ... for structuring a complex problem for getting advice?

(7) ... for international and intercultural communication?

(8) ... for explaining planning proposals?

(9) ... for addressing complex problems?

(10) ... for developing imaginative planning proposals?

(11) ... for identifying the locally most relevant issues?

(12) ... for developing spatially explicit proposals?

(13) ... for understanding different professional perspectives?

(14) ... for dealing with uncertain and insufficient information?

(15) ... for using different visualization techniques?

(16) ... for integrating expert information in planning proposals?

(17) ... for interpreting diverse and complex data?

(18) ... for deriving missing information?

(19) ... for synthesizing information and knowledge?

(20) ... for working with experts and stakeholders?

(21) ... for up- and downscaling information and knowledge?

(22) ... for presenting in public?

(23) ... for using information technology?
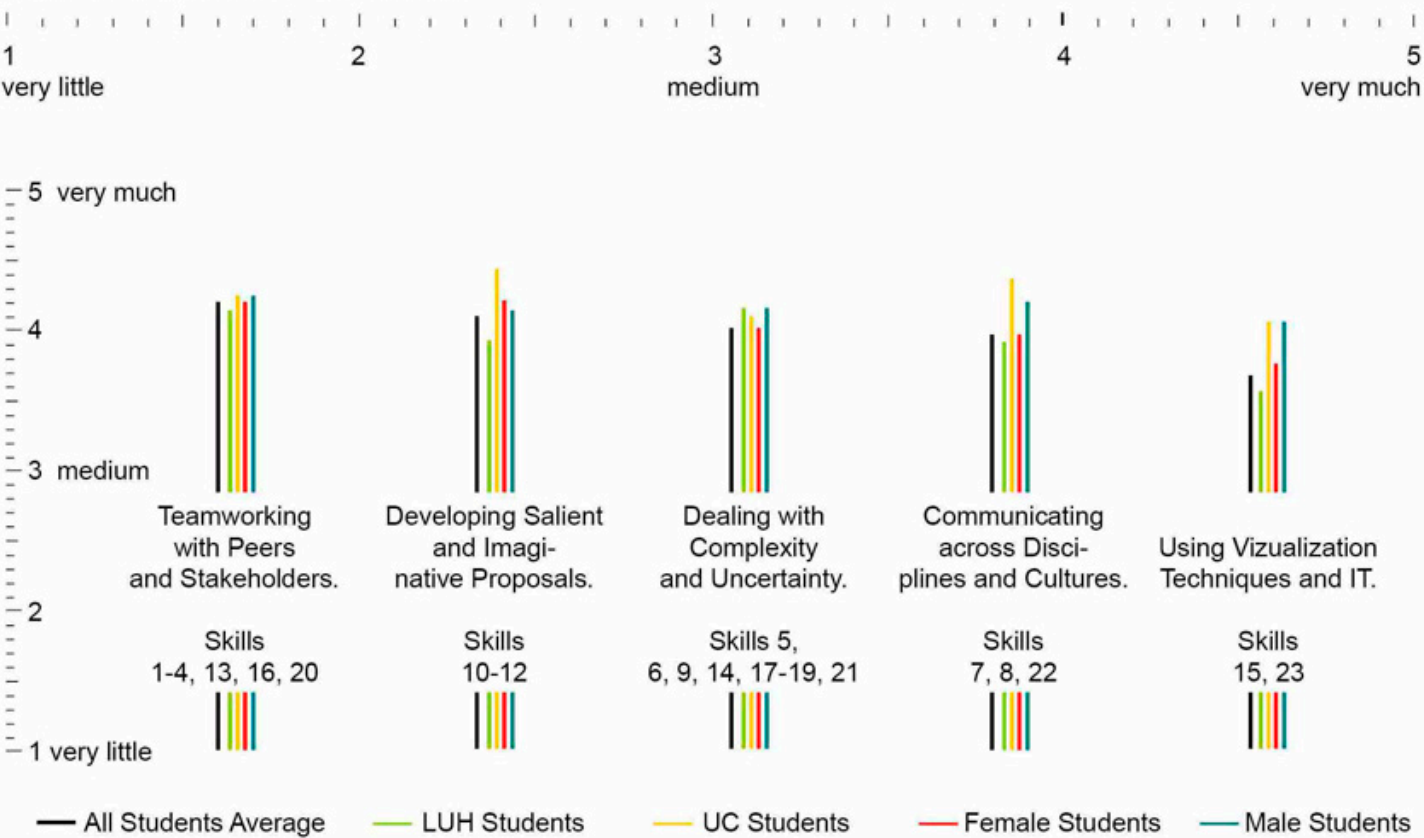

Figure 9. Perceived workshop contributions to the acquisition of planning skill. Means of scores provided by the participants of the whole student group $(N=30)$, as well as separately for students from LUH $(N=12)$, UC $(N=18)$, female students $(N=19)$, and male students $(N=11)$.

To gain understanding of the types of skills to whose development the workshop particularly contributed to, three skills categories were defined and average evaluation values calculated. The skills category "teamwork with peers and stakeholders" was evaluated best, followed by slightly less average values for "developing salient and imaginative proposals" and "dealing with complexity and uncertainty". Least average values were achieved for "communicating across disciplines and cultures", and "using technology". In addition to examining overall average values for individual skills and skill categories, the evaluation data was further assessed concerning differences in responses between different student cohorts. 
Looking at the average evaluation value across all skills, LUH students exactly matched the general average value of 4.0 units, while UC students evaluated slightly more positive (4.2 units). Male LUH students provided more positive ratings than female LUH students (4.4 and 3.9 units, respectively), and female UC students were more positive than their male co-students (4.4 and 4.2 units, respectively).

Greatest differences in the evaluation of individual skills by different student cohorts were found for "working with experts and stakeholders" and "developing spatially explicit proposals" that both received about 0.6 units more positive ratings by UC students than by their LUH colleagues. In contrast, LUH students were 0.4 units more positive than UC students about the workshop's contribution to skills for addressing complex problems. Female students found the workshop more effective in teaching skills for considering critique in planning proposals and understanding different professional perspectives ( 0.6 and 0.5 units higher than males, respectively). Male participants provided about 0.5 units higher ratings than females in evaluating skills for time management and deriving missing information.

The differences between average student cohort evaluations are also apparent in the comparison of the average values given for some planning skills categories. "Developing salient and imaginative proposals", "communicating across disciplines and cultures", and "using technology" were all evaluated more positive by UC students than by their LUH counterparts. The latter two skills categories also saw differences between more positive evaluations by male students than female students. Only marginal differences between student cohort evaluations are seen for "teamworking with peers and stakeholders" and "dealing with complexity and uncertainty".

The participatory observation data supported the described learning developments. It seemed that students - after one or two days of getting acquainted with each other and the teaching process — engaged very enthusiastically in their work. Students intensively discussed, worked, and collaborated to understand the planning procedures, to share factual information, and to reflect upon different perspectives. The workshop was perceived as stressful, but in a positive sense, allowing for great learning effects in little time. Students became thoroughly engaged in their work and were eager to improve their plans and proposals, even after a full workshop day. The intermediate presentations were regarded of great importance, and spurred intense collaborative efforts for finishing the planning products in time. Students increasingly developed understanding of the workshop process and the alternative futures planning method, and developed procedures for effectively communicating across language and cultural barriers.

The observation further suggested that the workshop's success in teaching planning skills was mainly due to the three features: (a) the multiple changes in perspectives required; (b) the time pressures and the forced revision and structured process; and (c) the several exchanges with stakeholders. The changes of perspectives forced students to actively consider different relevant landscape processes and stakeholder interests. Time pressures made students develop ideas rapidly, and the potential for future revisions helped in raising planning quality. The conversion of drawings into GIS seemed to be particularly useful in forcing greater precision and another loop of revision, while the more professional illustration enhanced students' self-confidence. Stakeholder collaborations compensated for most students' little factual knowledge about the study area and relevant landscape functions, and helped enhancing the credibility and relevance of the proposals. 


\section{Discussion and Conclusions}

Despite the limited "net" studio working time of only about $26 \mathrm{~h}$, the workshop yielded several result. Six substantially different and quite elaborated proposals were generated for the future landscape development of the region. The produced maps and impact evaluations found the interest and attention of local planners and decision makers. Asked about their interpretation of the quality of the six developed alternative futures, the local experts did not select a single one but argued that a consensus plan was needed that integrated the "best" projects from each alternative. A preliminary draft of such a "seventh alternative", developed a live-experiment in the final workshop meeting together with stakeholder, was interpreted by the local actors as being a quite good proposal. The proposal's quality was seen in both its substantive content as well as in its recognition of the governance structure and political reality of the region. Furthermore, the workshop seems to have spurred substantial learning among students about relevant planning understanding and skills. Planning understanding increased concerning the challenges, objectives, products, and possible success measures of scenario-based landscape planning. However, students' understanding of the framework and appropriate methods changed relatively little, which may be due to difficulties of students to comprehend the complex workshop process. The fact that many positive learning effects became only apparent in the ex-post questionnaire, which was handed out eight weeks after workshop completion, suggests that students sometimes require additional time to reflect learning experiences. Improvements of planning skills were reported concerning for collaboration, the creative planning of alternative futures, dealing with complexity and uncertainty, and communication. Skills development for using technology was lower, reflecting the little emphasis put on this aspect in the workshop design.

Various aspects of the workshop pedagogy seem to have been particularly effective in facilitating student learning (and had purposely been decided for by Carl Steinitz in the design of the workshop process):

- Many decisions about the scope of the workshop planning problem, the methods and expected outputs were pre-defined by the faculty. This one the one hand limited students' freedom to define their procedures (compared with a semester-long studio), but minimized time needed for orientation and enabled an immediate start of the planning process.

- All interim results, ideas, and planning proposals of student teams were publicly presented and made available for use by other groups (e.g., the long table of change proposals). This limited the personal attachment of students to "their" particular ideas and facilitated collaborative planning and more objective searches for appropriate solutions.

- Student groups were always mixed by disciplinary background and nationality. This made teamwork more difficult but also enhanced mutual understanding and facilitated practicing communication skills and intercultural collaboration.

- Student team composition and focus was changed from process and evaluation themes to different stakeholder interests after the mid-workshop presentation. This procedure had the benefit that stakeholder interest teams included members knowledgeable about different landscape processes who now served as quasi-experts on their theme. Also, students further enhanced teamwork skills in being required to again adjust to a new group setting. 
- The time provided for working periods was strictly limited. This, on the one hand, led to a relative crudeness of initial diagrams. On the other hand, it fostered concise thinking, facilitated rapid development and concretization of ideas and allowed for iterative improvement and intertwined collaboration between student groups. The time limitations of presentations to only two minutes also fostered conciseness and thoughtful preparation.

- Rotating the obligation to present interim results between students enhanced individual skills for public speaking.

- General "time-outs" for addressing questions in public enabled joint learning across all student groups and the possibility to build-upon each other's works.

- Providing examples and templates for expected products in each planning step seemed to enhance understanding of the workshop process among students. As suggested by student reporting, the use of pre-determined color code schemes for drawing process models, change diagrams and projects, for completing evaluations and land use maps was essential to allow for mutual understanding, quick presentations, and joint learning.

In addition to general challenges such as communication issues and time constraints, important issues were problems in understanding the terminology of the framework methods and students' difficulties in keeping up with the several changes of perspectives required. In being trained as environmental planners, they experienced problems in adopting unilateral perspectives for educational purposes.

The evaluation methodology yielded interesting insights. However, it became apparent that much time was needed during the workshop for filling out the surveys and questionnaires, as well as after the workshop for digitalization, coding, and analysis. Furthermore, some students had difficulties in comprehending the questionnaire on planning understanding. While they were asked to imagine that they would be independent consultants to the region, they assumed that we asked them in their role as students, and responded with respect to their tasks in the workshop. To assess changes in planning skills, future evaluations should rather use a smaller number of quantitative survey questions. These would be fast to complete and could be used at the beginning and several times over the course of the workshop. If changes in planning understanding should be assessed, appropriate time must be provided. Since this evaluation showed that changes in planning understanding sometimes only become apparent with some time for reflection, the respective questionnaires should be handed out at two times, once at the beginning and once some time after the workshop. This principle should also be considered in the teaching evaluations conducted at universities.

An interesting aspect for further exploration is the question of how pedagogic workshops can not only contribute to student learning but also yield real-world impact. This has not been evaluated in the Cagliari case study, although the reactions of participating local actors and decision-makers suggested that they intended to consider the workshop results as inspiration for further planning in practice. Lessons on this issue can be learned from research in the field of real-world learning for sustainability, e.g., at the School of Sustainability at Arizona State University [13].

Further research is needed to test the generalizability of the findings from this workshop to other case studies. An interesting issue for further reflection is therefore to assess if the learning success as achieved in this case study workshop would be replicable in other cases without the long-time teaching experience and the charismatic personality of the leader of the faculty team. 


\section{Acknowledgments}

We acknowledge the participation of students, educators and stakeholders in the workshop. We are further grateful for the involvement of Tess Canfield in the workshop implementation and the design of the survey. Christian Albert acknowledges funding from a dissertation scholarship of the German National Academic Foundation (Studienstiftung des Deutschen Volkes). We further acknowledge support by the German Academic Exchange Service (DAAD), Deutsche Forschungsgemeinschaft, and Open Access Publishing Fund of Leibniz Universität Hannover.

\section{Author Contributions}

Christian Albert, Christina von Haaren, Juan Carlos Vargas-Moreno and Carl Steinitz conceptualized the research and evaluation design and implemented the workshop. Christian Albert led the writing of the manuscript. Christina von Haaren, Juan Carlos Vargas-Moreno and Carl Steinitz contributed to manuscript writing.

\section{Conflicts of Interest}

The authors declare no conflict of interest.

\section{References}

1. Hulse, D.W.; Branscomb, A.; Payne, S.G. Envisioning Alternatives: Using Citizen Guidance to Map Future Land and Water Use. Ecol. Appl. 2004, 14, 325-341.

2. Steinitz, C.; Steinitz, C.; Arias, H.; Bassett, S.; Flaxman, M.; Goode, M.; Maddock, T.; David, M.; Peiser, R.; Shearer, A. Alternative Futures for Changing Landscapes: The Upper San Pedro River Basin in Arizona and Sonora; Island Press: Washington, DC, USA, 2003; p. 202.

3. Carpenter, S.R., Pingali, P., Bennett, E., Zurek, M., Eds. Ecosystems and Human Well-Being: Scenarios; Island Press: Oxford, UK, 2005; Volume 2.

4. Steinitz, C. A Framework for Theory Applicable to the Education of Landscape Architects (and Other Environmental Design Professionals). Landsc. J. 1990, 9, 136-143.

5. Shearer, A.W. Approaching scenario-based studies: Three perceptions about the future and consiederations for landscape planning. Environ. Plan. B 2005, 32, 67-87.

6. Xiang, W.N.; Clarke, K.C. The use of scenarios in land-use planning. Environ. Plan. B Plan. Des. 2003, 30, 885-909.

7. Alcamo, J. Environmental Futures: The Practice of Environmental Scenario Analysis (Developments in Integrated Environmental Assessment); Jakeman, A.J., Ed.; Elsevier: Amsterdam, The Netherlands, 2008; Volume 2.

8. Albert, C.; Zimmermann, T.; Knieling, J.; von Haaren, C. Social learning can benefit decision-making in landscape planning: Gartow case study on climate change adaptation, Elbe valley biosphere reserve. Landsc. Urban Plan. 2012, 105, 347-360.

9. Antrop, M.; Rogge, E. Evaluation of the process of integration in a transdisciplinary landscape study in the Pajottenland (Flanders, Belgium). Landsc. Urban Plan. 2006, 77, 382-392. 
10. Luz, F. Participatory landscape ecology-A basis for acceptance and implementation. Landsc. Urban Plan. 2000, 50, 157-166.

11. Selman, P. Community participation in the planning and management of cultural landscapes. J. Environ. Plan. Manag. 2004, 47, 365-392.

12. Shearer, K.S.; Xiang, W.N. Representing multiple voices in landscape planning: A land suitability assessment study for a park land-banking program in Concord, North Carolina, USA. Landsc. Urban Plan. 2009, 93, 111-122.

13. Brundiers, K.; Wiek, A.; Redman, C.L. Real-world learning opportunities in sustainability: From classroom into the real world. Int. J. Sustain. High. Educ. 2010, 11, 308-324.

14. Selman, P.H. Planning at the Landscape Scale; Routledge: London, UK, 2006.

15. Albert, C.; Moreno, J.C.V. Planning-Based Approaches for Supporting Sustainable Landscape Development. Landsc. Online 2010, 19, 1-9.

16. Krätzig, S.; Warren-Kretzschmar, B. Using Interactive Web Tools in Environmental Planning to Improve Communication about Sustainable Development. Sustainability 2014, 6, 236-250.

17. Vakil, A.; Marans, R.W.; Feldt, A. Integrative Planning Workshops: The Michigan Experience. J. Plan. Educ. Res. 1990, 10, 61-69.

18. Lusk, P.; Kantrowitz, M. Teaching Students to Become Effective Planners through Communication: A Planning Communications Studio. J. Plan. Educ. Res. 1990, 10, 55-59.

19. Frank, A.I. Three Decades of Thought on Planning Education. J. Plan. Lit. 2006, 21, 15-67.

20. Lang, J. Teaching Planning to City Planning Students. An Argument for the Studio/Workshop Approach. J. Plan. Educ. Res. 1983, 2, 122-129.

21. Agouridas, V.; Race, P. Enhancing Knowledge Management in Design Education Through Systematic Reflection Practice. Concurr. Eng. 2007, 15, 63-76.

22. Brown, R.D.; Hallett, M.E.; Stoltz, R.R. Student learning styles in landscape architecture education. Landsc. Urban Plan. 1994, 30, 151-157.

23. Kvan, T.; Jia, Y. Students' learning styles and their correlation with performance in architectural design studio. Des. Stud. 2005, 26, 19-34.

24. Roberts, A. Cognitive styles and student progression in architectural design education. Des. Stud. 2006, 27, 167-181.

25. Lehmann, M.; Christensen, P.; Du, X.; Thrane, M. Problem-oriented and project-based learning (POPBL) as an innovative learning strategy for sustainable development in engineering education. Eur. J. Eng. Educ. 2008, 33, 283-295.

26. Grant, J.; Manuel, P. Using a Peer Resource Learning Model in Planning Education. J. Plan. Educ. Res. 1995, 15, 51-57.

27. Stoltz, R.R.; Brown, R.D. The application of a pedagogical framework to the design of university courses. Landsc. Urban Plan. 1994, 30, 159-168.

28. Wiek, A.; Withycombe, L.; Redman, C. Key competencies in sustainability: A reference framework for academic program development. Sustain. Sci. 2011, 6, 203-218.

29. Wiek, A.; Xiong, A.; Brundiers, K.; van der Leeuw, S. Integrating problem-And project-based learning into sustainability programs. Int. J. Sustain. High. Educ. 2014, 15, 431-449.

30. Rieckmann, M. Future-oriented higher education: Which key competencies should be fostered through university teaching and learning? Futures 2012, 44, 127-135. 
31. Foley, R.W.; Petrucci, D.; Wiek, A. Imagining the Future City. Issues Sci. Technol. 2014, XXXI, $80-90$.

32. Steinitz, C. World conference on education for landscape planning. Landsc. Urban Plan. 1986, 13, 329-332.

33. Linke, H. Landscape planning education in European socialist countries. Landsc. Urban Plan. 1986, 13, 359-366.

34. Kiemstedt, H. The education of landscape architects and planners in West. Germany and Western Europe: Development, present situation and perspectives. Landsc. Urban Plan. 1986, 13, 379-387.

35. Steinitz, C.; Abis, E.; von Haaren, C.; Albert, C.; Kempa, D.; Palmas, C.; Pili, S.; Vargas-Moreno, J.C. Alternative Futures for the Metropolitan Area of Cagliari-The Cagliari Workshop, an Experiment in Interdisciplinary Education; Gangemi Editore: Rome, Italy, 2010.

36. Steinitz, C. A Framework for Geodesign: Changing Geography by Design; ESRI Press: Redlands, CA, USA, 2012.

37. Scholz, R.W.; Tietje, O. Embedded Case Study Methods: Integrating Quantitative and Qualitative Knowledge; Sage Publications: New York, NY, USA, 2001.

38. Yin, R.K. Case Study Research: Design and Methods, 3rd ed.; Sage Publication Inc.: Thousand Oaks, CA, USA, 2013.

39. Hancock, D.R. Doing Case Study Research; Teachers College Press: New York, NY, USA, 2014.

40. Barbour, R. Introducing Qualitative Research. A Student's Guide to the Craft of Doing Qualitative Research; Sage Publications Ltd.: Thousand Oaks, CA, USA, 2008.

41. Hay, I., Ed. Qualitative Research Methods in Human Geography, 2nd ed.; Oxford University Press: New York, NY, USA, 2005.

42. Merriam, S.B. Qualitative Research: A Guide to Design and Implementation; John Wiley \& Sons: Manhattan, NY, USA, 2014.

43. Jick, T.D. Mixing qualitative and quantitative methods: Triangulation in action. Adm. Sci. $Q$. 1979, 24, 602-611.

44. McMillan, J.H., Schumacher, S., Eds. Research in Education: Evidence-Based Inquiry; Pearson Higher: London, UK, 2014.

45. Lewis, J.L.; Sheppard, S.R.J. Culture and communication: Can. landscape visualization improve forest management consultation with indigenous communities? Landsc. Urban Plan. 2006, 77, 291-313.

46. Schroth, O.; Lange, E.; Sheppard, S.R.J.; Schmid, W.A.; Hayek, U.W. Multiple-Case Study of Landscape Visualizations as a Tool in Transdisciplinary Planning Workshops. Landsc. J. 2011, $30,53-71$.

(C) 2015 by the authors; licensee MDPI, Basel, Switzerland. This article is an open access article distributed under the terms and conditions of the Creative Commons Attribution license (http://creativecommons.org/licenses/by/4.0/). 